\title{
Successful Treatment of Congenital Chylothorax Using Fibrin Glue
}

Sir,

Chylothorax is the most common etiology of fetal and neonatal pleural effusion. ${ }^{1}$ We are reporting a case of persisting congenital chylothorax which was difficult to manage and resistant to various conventional therapeutic options.

A $2.5 \mathrm{~kg}$ female neonate was delivered at home by vaginal route, to second gravida mother at 38 weeks gestation. The antenatal period was uneventful. The baby was apparently well for first 7 days of life, when she developed fast breathing which progressively increased by day 11 of life and was brought to the Referral Neonatal Unit. At admission the skin temperature was $30.8^{\circ} \mathrm{C}$, the infant was hypoxic on room air $\left(\mathrm{SPO}_{2} 78 \%\right)$. The heart rate was 173 per minute, respiratory rate 67 per minute with intercostal and subcostal retractions and nasal flaring. On respiratory examination trachea was shifted to right side with stony dull note and decreased breath sounds on left side. Radiograph of chest showed homogenous opacity with obliteration of costophrenic angle on left side and mediastinal shift to the right. About $300 \mathrm{ml}$ yellow fluid was drained through a chest tube. Biochemical analysis of the aspirate revealed protein $5.6 \mathrm{gm} \%$, sugar133 $\mathrm{mg} \%$, cholesterol $112 \mathrm{mg} \%$ and triglyceride $708 \mathrm{mg} \%$. Total cell count was $1600 \mathrm{~mm}^{3}$, predominantly lymphocytes. Culture for pyogenic organisms was sterile. Sepsis screen was positive. The infant was put on ventilator on SIMV mode, chest tube was inserted and antibiotics were started., Respiratory distress settled with insertion of chest tube and infant was extubated after 14 hours of ventilation. On day 14 of life, infant was started on a medium chain triglyceride formula (SIMYL MCT) which was gradually increased to $120 \mathrm{ml} / \mathrm{kg}$ by spoon feeds. Triglyceride level reduced from $708 \mathrm{mg} / \mathrm{dl}$ to 360 $\mathrm{mg} / \mathrm{dl}$ and cholesterol reduced from $112 \mathrm{mg} / \mathrm{dl}$ to $56 \mathrm{mg} / \mathrm{dl}$ over one month of MCT feeds. After starting the Simyl MCT formula, inter costal drainage gradually stopped within 7 days. Chest tube was removed on day 21 of life when there was no drainage for 48 hours and no respiratory distress. Respiratory distress increased on day 28 and repeat ultrasound examination of chest revealed left sided pleural effusion with maximum width of $6.2 \mathrm{~mm}$. About $90 \mathrm{ml}$ of chyle was aspirated with improvement in respiratory distress. On day 44, Lymphoscintigraphy was done after injecting Tc99m sulfur colloid intradermally. Four hour image showed abnormal accumulation of tracer in the left hemithorax suggestive of abnormality of pulmonary lymphatics. By day 59 of life, $1200 \mathrm{ml}$ chylous fluid had been aspirated over 15 occasions. On day 59 of life injection octreotide was started as I.V. infusion in dose of $3 \mu \mathrm{g} /$ $\mathrm{kg} / \mathrm{min}$ which was gradually increased to $10 \mu \mathrm{g} / \mathrm{kg} / \mathrm{min}$ over the next 7 days.. However, accumulation of chylous fluid in pleura continued unabated and thoracocentesis was required for respiratory distress every $4^{\text {th }}$ to $5^{\text {th }}$ day. A total of $1000 \mathrm{ml}$ chyle was drained over 13 occasions during the 4 weeks of octreotide therapy suggestive of poor response. On day 94 of life surgical intervention was performed. This consisted of left posterolateral thoracotomy with spraying of fibrin glue. No definite leak of chyle could be identified. There were gross pleural adhesions especially at diaphragm and a loculus $5.5 \mathrm{~cm}$ in size filled with chyle under pressure was seen. Adhesionolysis was done and chyle was drained. Minor ooze of clear fluid was observed in posterior mediastinum.

The prepared fibrin glue was applied over pericardium, anteromedial surface of diaphragm,over dissected area all along the aorta, apex and over lung surface. Thoracostomy tube was placed in posterior mediastinum and there was no drainage after 24 hours. The post-operative course was uneventful. Infant was shifted to breast feeds and was discharged on $10^{\text {th }}$ post operative day.

The initial management of chylothorax is identification and evacuation of the pleural effusion.

Pleurodesis with fibrin glue effectively ablated the chylous leak in case reports. ${ }^{2}$ Surgical ligation of the thoracic duct represents definitive treatment of unremitting chylothorax.

Physicians should maintain a high index of suspicion for chylothorax and promptly identify pleural effusions to optimize patient care.Failure of non-operative therapies should result in early minimally invasive surgical intervention to avoid a catastrophe.

NB Mathur, Bijender Singh

Ajay Kumar, SK Aggarwal ${ }^{1}$

Department of Pediatrics and ${ }^{1}$ Pediatric Surgery, Maulana Azad Medical College, New Delhi

Dr NB Mathur, Professor of Pediatrics, Maulana Azad Medical College, New Delhi 110002, IndiaTelephone 011-23073606 Email :drnbmathur@vsnl.com

[DOI-10.1007/s12098-009-0118-X]

\section{REFERENCES}

1. Beghetti M, La Scala, G, Belli D, Bugmann P. Etiology and management of pediatric chylothorax. J Pediatr 2000;136: 653-658.

2. Nquyen D, Tchervenkov CI. Successful management of post operative chylothorax with fibrin glue in a premature neonate. Can J Surg 1994;37:158-160. 